Windows into the theories-in-use of ELT community: A generic and corpus analysis of ELT blurbs across four decades

Chahkandi, Fateme

Department of Foreign Languages, University of Isfahan, Iran (f.chahkandi@ gmail.com)

Zeinali, Mohammad

Department of Humanities, Farhangian University, Birjand Branch, Iran (mohammadzeinali@ymail.com)

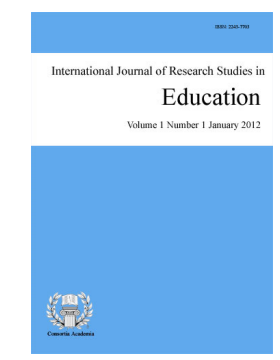

ISSN: $2243-7703$ Online ISSN: 2243-7711

OPEN ACCESS

Received: 10 April 2015

Revised: 31 May 2015

Accepted: 3 June 2015

\title{
Abstract
}

This study employed corpus and genre analysis as two useful tools to explore theories-in-use of the ELT community across 4 last decades. Analysis of the move-step sequence of the back cover blurbs revealed a 6-move generic pattern including advertising a book by selecting a slogan, establishing a niche, specification of the content, presentation of other components on the package, author endorsement, and propagating the book by means of extracts from teacher and students the overall purpose of which was to introduce the book and persuade the readers. From among the moves, the second one was explicitly and implicitly concerned with delineation of the theoretical framework underpinning the work. Examination of the key word concordances also indicated that, unlike what literature claimed to be the case (e.g. Bastrukmen, 1999), theories are well-reflected and well-documented in the ELT blurbs. However, the ELT community has adopted a selective approach toward theoretical orientations and that it values what is practical and of use at the classroom level. The implications are then discussed with the regard to theorists and practitioners, publishing agencies and teachers and students alike.

Keywords: ELT blurbs; corpus analysis; genre analysis; theories-in-use; concordance; ELT community 


\section{Windows into the theories-in-use of ELT community: A generic and corpus analysis of ELT blurbs across four decades}

\section{Introduction}

The introduction of English as a lingua franca gave rise to a preponderance of language teaching and learning theories or what Stern (1985) called the "method boom" (p. 249). Some of these methods (e.g. Audiolingualism) provide discrete and distinct paths to language teaching whereas for others (e.g. Community Language Learning and Suggestopedia) the underpinning theoretical and practical orientations overlap considerably. The reason why each method led to the development of the other was that with the accumulation of experience and experimentation researchers and teachers alike became increasingly skeptical about the effectiveness of the pedagogy to realize its stated goal of fostering communicative capability in learners. The search for an alternative method was hastened by developments in disciplines of not only linguistics and psychology, but also anthropology and sociology as well as other subdisciplines of ethnography, ethnomethodology, pragmatics, and discourse analysis.

With these changing winds and shifting sounds (Marckwardt, 1972, p. 5), textbooks appeared and reappeared purported to subscribe themselves with theoretical principles and conceptual specifications of particular methods. As a site where the accepted ideologies of the community are put into practice, blurbs function to mark key foundational elements of the books. To persuade the reader and to inform her/him of the content of the book, back cover blurbs can employ a plethora of promotional strategies one of which is to subscribe themselves with the latest theories in vogue. That is, they can take advantage of "theories of beliefs" (Robinson, 1993) of the teaching community to bring themselves in line with the existing trends. However, contrary to the expectation, Todova (1997) indicated that blurbs mainly reflected the theories-in-use and there was little compatibility between theorists and textbook writers. In other words, the premises put forward by the theorists were not all welcomed warmly by the practitioners. The purpose of this research is to inquire whether the back cover of the ELT books published in different eras of teaching methodology represents the category of the method or theory purported to be in vogue in that era or whether there is considerable overlap between their elements in-focus.

As one of the first studies which investigated the role of socio-cultural factors in shaping a genre, Kathpalia (1997) analyzed the book blurbs of international and local Singapore-based publishers. Analysis of the corpus indicated that blurbs consisted of six moves including: headlines, justifying the book, appraising the book, establishing credentials, endorsements(s), and targeting the market. Furthermore, local blurbs indicated universal tendencies in terms of rhetorical conventions of professional discourse community. However, culture-specific tendencies were also observed in sequencing the moves and their linguistic realizations as local writers gave preference to grammatical correctness over stylistic deviant strategies.

Gea-Valor (2005) defined blurbs as a genre characterized by its own communicative purpose i.e. persuading the readers, and analyzed 60 blurbs displayed on the websites of four widely-known publishing and bookselling companies including Penguin, Ballantine, Routledge, and Barnes \& Noble. She identified a three-part generic structure including a) information about the content of the book mainly including plot or argumentative lines according to literary genre in question, b) evaluation by means of extracts from reviews whose main purpose was to recommend the book by praising the qualities of the book and the author, c) about the author part which encompassed information about the author's professional background such as publications, awards, interests, and biography. From among these moves, only 1 and 3 were considered obligatory by the researcher.

In an attempt to delve into "theories-in-use of teaching community", Basturkmen (2009) analyzed back covers of seven of best-seller ELT books in New Zealand first, for their sequential pattern of organization and 
A generic and corpus analysis of ELT blurbs across four decades

second, for key words concordances and collocations. Analysis of the corpus yielded a four-move generic structure including identifying the market niche, establishing language teaching theory, presenting credentials and introducing supplementary items in the course book package. Based on these observations, she concluded that the ELT community favored an a-theoretical position since only one of the 4 moves dealt with statement of theory. Second, the ELT community valued practical solutions to the problems and sought real-world, ready-made materials that worked at classroom level. Additionally, language learning in the ELT community consisted of learning a set of grammatical structures and vocabulary items since they appeared most frequently in the blurbs. Finally, the ELT community advocated practices and techniques extracted from cognitive theories of learning.

Önder (2013) studied the cross-cultural analysis of book blurbs in fictions from two booksellers' websites, Amazon United Kingdom and Okuoku Turkey (1999-2011). The generic analysis of 95 book blurbs revealed that both corpora shared four common moves including complimenting the author, book description, book promotion, and author's biography. Two moves, however, were specifically distributed in Amazon UK data - justifying the book by establishing a niche and author's website/blog. On the other hand, a different move was found only in the Turkish data including involving the reader in the text by raising questions. Based on these observations, she concluded that cross-cultural variations in the generic structure of blurbs were not highly marked though some slight differences could be witnessed.

As the short review presents, not only is the number of studies on content analysis of blurbs scarce, but also with the exception of Basturkmen (2009), no other studies are carried out on the ELT blurbs. The significance of investigating the back cover blurbs of ELT textbooks resides in the fact that they can reveal significant information about the theories-in-use of the ELT community. Further, the importance of this investigation is enhanced if comparisons are made across the decades where competing theories appeared and vanished. This way, valuable insights can be gained about the degree to which the textbooks adhered to the trendy theories and about the differences being made in the content of the books during the eras. To this aim, a two-level analysis of blurbs- macro analysis of the generic structure of the blurbs and micro content analysis of word frequency and concordances - is carried out and the results are compared across the decades. Hence, the following research questions are addressed in this study:

$>$ What is the generic structure of the blurbs? Is there any difference in the generic structures across the decades?

$>\quad$ What do key word concordances reveal about the theories-in-use of ELT community?

\section{Method}

\subsection{Corpus}

The corpus for the current study consists of the back cover blurbs of 54 books including 7 books in 1980s and before, 17 in 1990s, 21 in 2000s, and 9 blurbs up to 2014. The back cover blurbs of the ELT books were typed into the Microsoft Words and were analyzed for their sequential pattern of organization and words frequency across the decades. Table 1 shows the corpus in detail including the names of the books, their publication year, the level for which they are written as well as the associated press.

\subsection{Procedure}

The corpus included in the study was first analyzed for its genre construction based on Swales' (1990) approach which was further expanded by Bhatia (1993), Dudley-Evans (1994), Santos (1996), and Yunxia (1997). As Swales characterized it genre serves a particular discourse community and is glossed as a communicative event with a communicative purpose and a regular pattern of moves and steps. According to this 
Chahkandi, F., \& Zeinali, M.

definition, one can identify ELT blurbs as a communicative event whose aim is to present the book and depict its content outline. In the analysis of generic organization of blurbs the following operational definitions were adopted:

A move has a minor communicative purpose which contributes to the major communicative purpose of the genre (Santos, 1996).

$>\quad$ A step is a lower unit which provides the writer with more details on the options accessible to him (Dudley- Evans \& St. John, 1998).

In the second phase, the content of blurbs was analyzed for word collocations using LexisNexis Software for each decade separately and the results were compared and contrasted chronologically and with reference to the theories and methods specific to each era. That is, the blurbs were analyzed to examine whether they adhered to the underlying conceptualizations particular to each era or whether they reflected a general tendency among book publishers. To do so, a sub-corpus of Moves 2 and 3 (moves delineating theoretical framework) were analyzed utilizing the software and from the wordlist given words denoting theory claims such as grammar, vocabulary, pronunciation, skills, culture, syllabus, communicative, and authenticity were selected to make comparisons across the decades.

\section{Table 1}

Characteristics of the Course Books Included in the Corpus

\begin{tabular}{|c|c|c|c|}
\hline Book name & Publication year & Level & Press \\
\hline $\begin{array}{l}\text { Breakthrough: a course in English } \\
\text { communication practice }\end{array}$ & 1977 & & Oxford Uni. \\
\hline American streamline & 1983 & departures & Oxford Uni. \\
\hline Head way & 1986 & Intermediate & Oxford Uni. \\
\hline Head way & 1988 & Upper intermediate & Oxford Uni. \\
\hline Head way & 1989 & Advanced & Oxford Uni. \\
\hline International Express Ways & 1989 & & prentice Hall \\
\hline Mode & 1989 & & Collins ELT \\
\hline The new Cambridge & 1990 & 2 & Cambridge uni. \\
\hline Touchdown & 1990 & & Longman \\
\hline Head way & 1991 & advanced & Oxford Uni. \\
\hline Street Ahead & 1992 & & Oxford Uni. \\
\hline Streetwise & 1992 & & Oxford Uni. \\
\hline Interchange & 1994 & & Cambridge uni. \\
\hline Spectrum & 1994 & & Prentice Hall \\
\hline Look Ahead & 1995 & & Longman \\
\hline Main street & 1995 & & Oxford Uni. \\
\hline Express Way & 1996 & & prentice Hall \\
\hline Freeway & 1996 & advanced & Longman \\
\hline Move up & 1996 & & Macmillan \\
\hline English Panorama & 1998 & advanced & CUP \\
\hline Gateways & 1998 & & Oxford Uni. \\
\hline New interchange & 1998 & & Cambridge uni. \\
\hline Open House & 1998 & & Oxford Uni. \\
\hline Transitions & 1999 & & Oxford Uni. \\
\hline Explorations & 2000 & & Oxford Uni. \\
\hline New Headway English course & 2000 & pre-intermediate & Oxford Uni. \\
\hline Pacesetter & 2000 & elementary & Oxford Uni. \\
\hline passages & 2000 & & Cambridge uni \\
\hline International express & 2001 & Upper-intermediate & Oxford Uni. \\
\hline American Headway 3 & 2003 & & Oxford Uni. \\
\hline
\end{tabular}


A generic and corpus analysis of ELT blurbs across four decades

Table 1 ... continued

\begin{tabular}{|c|c|c|c|}
\hline Book name & Publication year & Level & Press \\
\hline Innovations & 2003 & & Thomson ELT \\
\hline Power base & 2003 & & Pearson Edu \\
\hline Connect & 2004 & & Cambridge uni \\
\hline English in mind & 2005 & & Cambridge uni \\
\hline Know how & 2005 & & Oxford Uni. \\
\hline World link & 2005 & & Thomson ELT \\
\hline Worldview & 2005 & & Pearson Edu \\
\hline Messages & 2006 & & Cambridge uni \\
\hline Top Notch & 2006 & 1B & Pearson Edu \\
\hline Top Notch & 2006 & fundamentals & Pearson Edu \\
\hline World pass & 2006 & & Thomson ELT \\
\hline Step forward & 2007 & & Oxford Uni. \\
\hline International English & 2008 & & Hodder Education \\
\hline Passages & 2008 & & CUP \\
\hline Touchstone & 2008 & 1B & Cambridge uni \\
\hline Engage (second edition) & 2011 & 3 & OUP \\
\hline English for life & 2011 & Intermediate & OUP \\
\hline New Headway (4 ${ }^{\text {th }}$ edition) & 2011 & Elementary & OUP \\
\hline New Headway (4 ${ }^{\text {th }}$ edition) & 2011 & advanced & OUP \\
\hline English file (third Edition) & 2012 & Pre- Intermediate & OUP \\
\hline English file (third Edition) & 2012 & Intermediate & OUP \\
\hline English knowhow & 2012 & opener & OUP \\
\hline Natural English & 2012 & elementary & OUP \\
\hline English result & 2013 & & OUP \\
\hline
\end{tabular}

\section{Results}

\subsection{The Generic Structure of Blurbs}

Analysis of the ELT blurbs indicated a 6-move schematic structure each of which has its own communicative purpose while at the same time, contributing to the overall purpose of the blurb, introducing the book. Move 1, advertising the book by selecting a slogan, contains catch phrases and expressions which aim to suggest that language learning through this course is achievable and easy to do. The mottoes are selected in such a way that hints to the tile of the series and there usually exists a repetition of the title's key word in the statement. This is to imply where the title is taken from and what the rationale behind selecting the title is. The slogans are directed to both teachers (Takes students from how to can do in every lesson: English Result, 2013; The best way to get your students talking! English file third edition, 2012, Take your students to the top! Top Notch, 2006) and students (Speak English naturally! Natural English, 2012; Know how English works and how to use it! English KnowHow, 2012), or simply they are terms and expressions complementing the book (Engaging a new generation! Engage second edition, 2011; The world's most trusted English course, New headway elementary fourth edition, 2011). Notably, move 1 is not an obligatory one and it is only present in the textbooks published in 2010 and afterwards.

Move 2, establishing a niche, serves to identify the market niche by delineating the target group for which the book is written. Specifically, information is given about the age and language proficiency of the consumer group of the book. Moreover, it characterizes the book as part of a series and how it builds on the preceding and subsequent levels alongside the level to which the learner is expected to reach after completing the series. Additional information is also provided about improvements the current textbook has made over the previous editions as well as the number of units and modules presented in the book, general aim of the book, means of achieving it, and the syllabus type based on which the book is designed. Although Step 1_ presenting information about the target consumers_ and Step 2 _introducing other courses on the series_ form obligatory 
parts of move 2, Step 3 _determining methodological framework, primary objective of the course and means of delivering it_constitutes an optional part of move 3 and is thus sometimes transferred to the next move. An example of Move 2 is provided below:

Step 2: Spectrum is a complete six-level course Step 1: for adult and young adult learners of English Step 3: featuring a "unique" natural approach (underlying methodology) to language learning. Rich language input is provided in authentic conversations accompanied by receptive activities that help students absorb new functions, structures and vocabularies. Real-life language tasks (means of delivery) offer both focused practice and opportunities for natural interactions, promoting both fluency and accuracy (general aim). Students' progress from the beginning to the advanced level as they follow a comprehensive and carefully graded syllabus.

The third move, content specification, presents further details of how the content of the book is structured in terms of the coverage of the basic skills and sub-skills, treatment of grammar, vocabulary, pronunciation, culture, topic and tasks in addition to assessment, illustration and page layout. Explicit reference is also often made to the processes through which learning is believed to takes place, means of delivery of the processes, and methodological underpinnings of the course which is what is moved from the Step 3 of Move1. Finally, in addition to organizational facts about the curriculum, points are often made about the way it deals with affective factors such as students' confidence and motivation, their diverse learning styles, conversation management, critical thinking and learning strategies. Although it may not contain all the features discussed above, move 3 is also considered a compulsory one.

The next mandatory move, presenting other components on the package, offers what accompanies student book including work book, pronunciation book, teacher's guide, teacher's resource pack, audio and video cassettes, CDs and DVD, and assessment package. Further, there has been the addition of other multimedia resources including softwares, websites, Itoos, Itutors, Icheckers, multiROMs, content for mobile use, and other digital solutions in more recent courses. Some textbooks provide detailed information on what each of the items on the package contains. English Result (2013), for example, supplies the following information on this move:

$>\quad$ student DVD with the English result student's book includes real world documentary clips and authentic interviews for self-study and to use in class

$>\quad$ Itools digital resources for interactive whiteboards make English result even more enjoyable and motivating

$>\quad$ student's multiROM with the English result work book provides interactive listening, pronunciation and vocabulary practice

$>\quad$ teacher's DVD with the English result teacher's book shows English result in action in the classroom plus author commentary

$>$ English result student's website for more practice http://www.Oup.com/elt/result

The following optional move, author endorsement, fluctuates between the second and the last move and is employed to promote the book even further by linking it to the high status and professional background of the authors and through a complimentary and positive tone. The information provided in this move includes authors' experience in and contributions to the ELT profession, affiliation, current position, other publications in conjunction with professional and research interests. A sample text on this move is presented from Touchstone: IB (2008):

Michael McCarthy is Emeritus professor of applied linguistics at the University of Nottingham, where he specialized in the analysis of spoken English and contributed to the development of Cambridge international corpus. He is currently adjunct professor of applied linguistics at the Pennsylvania state university and the University of Limerick. He is the author of many tiles of 
A generic and corpus analysis of ELT blurbs across four decades

interest to teachers, including spoken language and applied linguistics. Well-known as an expert in teaching and learning of vocabulary, he is the co-author of the basic and upper-intermediate levels of vocabularies in use.

A newly-added optional move, propagating the book by means of extracts, in some recent textbooks also contains extracts of comments from teachers or students to further advertise the book. The example includes a sample text from New Headway: advanced (2011):

Teacher around the world comment on headway advanced:

This book would certainly be one of my first choices for this level: innovative, thought-provoking, linguistically challenging, yet resting on a long and solid tradition.

Table 2 indicates the occurrence of moves and steps in the book blurbs across different decades.

Table 2

Occurrence of Moves and Steps in the Back Cover Blurbs of Different Decades

\begin{tabular}{|c|c|c|c|c|c|c|c|c|c|}
\hline \multirow{2}{*}{$\begin{array}{l}\text { Publication } \\
\text { decade }\end{array}$} & \multirow{2}{*}{$\begin{array}{c}\text { Move } \\
1\end{array}$} & \multicolumn{3}{|c|}{ Move 2} & \multirow{2}{*}{ Move 3} & \multirow{2}{*}{ Move 4} & \multirow{2}{*}{ Move 5} & \multirow{2}{*}{ Move 6} & \multirow{2}{*}{$\begin{array}{r}\text { Total } \\
\text { blurbs }\end{array}$} \\
\hline & & Step1 & Step2 & Step3 & & & & & \\
\hline $1980 \mathrm{~s}$ & 0 & 6 & 7 & 7 & 7 & 6 & 3 & 0 & 7 \\
\hline $1990 \mathrm{~s}$ & 0 & 16 & 14 & 17 & 17 & 16 & 3 & 0 & 17 \\
\hline $2000 \mathrm{~s}$ & 3 & 20 & 15 & 20 & 21 & 19 & 3 & 0 & 21 \\
\hline 2010-2014 & 9 & 3 & 1 & 6 & 9 & 9 & 1 & 4 & 9 \\
\hline
\end{tabular}

As the frequency of moves in the table reveals, except for the Moves 1 and 6, other moves have been hold constant during the decades. Move 1 has been added from 2000s and move 6 from 2010 onwards. On the other hands, during the last years (2010-2013), there has been less emphasis on the level and age group for which the book is appropriate.

\subsection{Key Word Concordances}

Analysis of collocations and contexts in which key words have been found revealed significant facts about practical theories of ELT community in each decade.

1980s - During this decade, grammar was treated deductively through detailed and comprehensive explanation of all grammatical points. Its frequent co-occurrence with function and lexis indicate that these three elements constituted the core of what claimed to be "communicative syllabus" in that time. Examples of blurbs illustrate the point:

It is based on the authors" three-dimensional syllabus design which integrates functions, grammar, and situations. Each of the lessons offers practice in one or more functions, the grammatical forms needed to express these functions and the contexts in which the functions and grammar are used. (International Express Ways, 1989)

Grammar and vocabulary are taught and explained thoroughly, and all four language skills are systematically developed. (Headway, 1986)

Authenticity is used to describe naturalness of language, reading texts, and materials but no reference is made to authenticity of tasks and activities.

Units 2 and 4 provide skill practice based on authentic listening and reading texts. (Mode, 1989)

Authentic reading texts and unscripted listening passages for task-based activities. (Mode, 1989) 
There is a great emphasis on systematic development of all four language skills; however, no point is made about integration of skills, balanced presentation of 4 skills, or using them in communicative contexts.

Highly systematic skill development work, organized through a unique skill development sub-syllabus. (Headway, 1988)

The communicative syllabus systematically covers all the structures, functions and lexis required at this level. In addition, there are separate skill units throughout the course which help students approach reading, writing, listening and speaking with more confidence. (Mode, 1989)

A combination of both traditional methods of language teaching and more communicative approaches is stressed throughout the corpus; nevertheless, communicative syllabus is defined in terms of covering the basic vocabulary, structure, and functions of language.

The Headway series combines traditional methods of language teaching and more recent communicative approaches. (Headway, 1986)

The communicative syllabus systematically covers all the structures, functions and lexis required at this level. (Mode, 1989)

Several mentions have been made of vocabulary and there is one occurrence of vocabulary with lexical chunks:

A three-pronged approach to expanding vocabulary which comprises learning strategies, systems of vocabulary, and introducing lexical sets. (Headway, 1988)

Culture was not found throughout the corpus for this decade. The only mention of the entry was collocated with American language and American culture and no attention was paid to global culture and cross-cultural understanding.

Its use of American language and American culture and humor makes it the perfect book for students of English. (American streamline, 1983)

1990s - Explicit reference is made to the communicative approach underpinning the textbook with specification of its underlying philosophy. At the same time, the corpus indicates recommendation for a blend of communicative approach with traditional methods as the best method of tackling the content.

The underlying philosophy of the course is that language is best learned when used for meaningful communication. (New interchange, 1998)

The Headway series combines traditional methods of language teaching and more recent communicative approaches. (Headway, 1991)

While greater stress is put on communicative approach in this decade, structure is not ignored as the basic element of the curriculum. Specifically, it is considered as a foundation for communicative interaction.

A carefully structured grammar syllabus that provides a firm foundation for communicative exchanges. (Gateways, 1998)

Detailed treatment of grammar in two stages: first within the unit where it is introduced and secondly in a fuller version, suitable for self study and revision, in the Grammar Section at the back of the book. (Headway, 1991)

There is a more explicit allusion to genuinely communicative and cooperative activities such as information gap, community connection, task-based pair and small group activities as well as interviews. 
A generic and corpus analysis of ELT blurbs across four decades

Thorough, creative practice material includes information gap activities, role plays, songs, games, and opportunities for personal expressions. (Main street, 1995)

Role playing, cooperative learning, critical thinking, problem solving and community tasks offer students interactive, student centered learning that is relevant to the varies needs and interests.(Expressways, 1996)

Authenticity is embraced in broader sense: it includes not only authenticity of content and language but also of tasks and activities.

Rich language input is provided in authentic conversations accompanied by receptive activities that help students absorb new functions, structures and vocabularies. (Spectrum, 1994)

Real-life language tasks offer both focused practice and opportunities for natural interactions, promoting both fluency and accuracy. (Spectrum, 1994)

Systematic development of language skills is not only emphasized but attempt is also made to present a balanced view of the four skills in addition to integrating them in meaningful communicative context.

Treatment of four skills gives students a balanced view of language from the very beginning. (Open House, 1998)

Integrated and systematic practice of all four language skills. (Transitions, 1999)

In comparison to the previous decade, the core syllabus is widened including more elements of language such as structure, lexis, situations and function, themes, and phonological aspects.

A multi-skills syllabus integrating themes, structures, functions, vocabulary and pronunciation (New interchange, 1998)

There are signs of recognition of the global culture and the fact that English has no native speaker but is the language of international communication. However, as the blurbs reflect, English culture is still the privileged one to be taught.

New interchange is written in American English, but reflects the fact that English is the major language of international communication, and is not limited to any one country, region and culture. (New interchange, 1998)

Pronunciation is claimed to be worked on thoroughly and the contextual settings in which the word occur imply that native-like pronunciation and not intelligible one is the aim.

A through treatment of pronunciation. (New interchange, 1998)

Headway Pre-intermediate is accompanied by Headway Pre-intermediate pronunciation, which provides a range of supplementary exercises to practice all aspects of pronunciation. (Headway, 1991)

Explicit strategies including learning, critical thinking, conversation management, and vocabulary development ones are incorporated in the books of this era.

Key learning strategies integrated into each unit and consolidated in the Strategy Section review units. (Gateways, 1998)

Critical thinking strategies that encourage students to think in English. (Transitions, 1999) 
Chahkandi, F., \& Zeinali, M.

Important conversation management strategies that help students to get information they need to keep a conversation going. (Transitions, 1999)

Clarification strategies to give students the tools they need to navigate effectively through real-life English. (Gateways, 1998)

Vocabulary development strategies help students cope with new and unfamiliar vocabularies. (Main street, 1995)

Meaningfulness of contexts, tasks, communicative interactions, and content is highlighted while the entry is completely absent in the previous decade.

High-interest, cross-cultural topics that provides a context for meaningful language learning. (Gateways, 1998)

Abundant and meaningful practice materials reinforce language and skills at every stage of learning. (Open House, 1998)

It features English as tool of discovery in which authentic content provides both a context for meaningful language work and a basis for exploration of interesting adult topics. (Transitions, 1999)

2000s - A weak version of communicative methodology illuminates the underlying theory of the course while it does not lose sight of structure at the same time.

A communicative methodology which presents new language in context and allows students to become actively involved in the learning process. (Pacesetter, 2000)

The American Headway combines the best traditional methods with more recent approaches to make the learning of English stimulating, motivating and effective. (American Headway, 2003)

Both deductive and inductive methods of teaching grammar are recommended though the collocational context in which the entry occurs shows that precedence is given to inductive teaching of grammar. Further, grammar is claimed to be presented in a communicative context which implies form-focused component of grammar instruction.

Essential grammar: students learn grammar through either inductive or deductive techniques, depending on which are more effective and practical for that grammar item. (World link, 2005)

A strong grammar syllabus presented in authentic contexts, enabling learners to formulate rules and supported by grammar summaries in the Pocket Book. (International express, 2001)

Cognitive and learning strategies along with metacognitive ones are given equal attention. Earlier decades, however, failed to take into consideration metacognitive strategies.

Clear learning objectives and "check your progress sections" help students plan their learning and monitor progress. (English in mind, 2005)

The series introduces "unique conversation management" strategies, places special emphasis on teaching vocabulary and vocabulary - learning strategies, and offers exiting ideas for personalized learner-centered interactions. (Touchstone, 2008)

Culture is tackled globally and cross-cultural understanding is deemed as one of the primary objectives of the books.

Universal topics: students relate to world themes that provide the necessary context for learning 
A generic and corpus analysis of ELT blurbs across four decades

about the English language and global cultures. (World link, 2005)

A strong cross cultural element designed to sensitize learners to the relationship between language use and cultural context. (International express, 2001)

Students' background schemata are taken into consideration in developing syllabus and activities.

A collaborative approach to language work_recognizing that learners already know a lot, building on what they know, involving them in practicing and extending their knowledge. (International express, 2001)

Topic based review and reintegration of previously learned language. (Explorations, 2000)

Vocabulary is acknowledged in broader areas of collocations, lexical chunks, and phrasal verbs and strategies are offered to remedy the problems students experience when facing new words.

Word power sections focusing on key problem areas of lexis such as collocation, common confusions, phrasal verbs and on key vocabulary-building skills. (International express, 2001)

Systematic vocabulary syllabus, including dictionary training, and work on systems such as collocation. (American Headway, 2003)

Presents and practices vocabulary, collocations, fixed expressions and more idiomatic language. (Innovations, 2003)

Similar to the previous decade, language skills are employed in an integrated and contextualized way to foster language learning.

Integrated and systematic practice of all four language skills. (Explorations, 2000)

Integrated skill work, where all for skills are developed in context. (New Headway, 2000)

A greater variety of tasks is provided involving more groups of students and extending to out of class activities.

Three consolidation units in each level to revise and extend the language and skill taught through a variety of controlled and free activities including project work. (Pacesetter, 2000)

Pronunciation is worked out in an integrated way.

Pronunciation work, which is integrated at appropriate points. (American Headway, 2003)

Thorough attention to pronunciation. (Top Notch, 2006)

Personalization of skills and activities is explicitly focused.

The series introduces "unique conversation management" strategies, places special emphasis on teaching vocabulary and vocabulary - learning strategies, and offers exiting ideas for personalized learner-centered interactions. (Touchstone, 2008)

2010-2014 - Lexical bundles and prefabricated chunks are widely approved and belief about learning is shifted from structural learning to a lexical one.

Everyday expressions give students the language for practical situations. (English for life, 2011)

A focus on lexis and spoken language in a challenging language syllabus. (New Headway, 2011) 
Very useful and appropriate choice of areas. It's good to see a focus on features of lexis and spoken language. (New Headway, 2011)

Vague statements are put forward about syllabus content. Its specific characteristics are not established explicitly throughout the corpus although the context in which the items have occurred implies that it mainly consists of lexical sets extracted from a corpus of frequent expressions.

A perfectly-balanced syllabus with extensive resources at all levels. (New Headway, 2011)

It's a course with a new syllabus area called natural English: accessible, high frequency phrases which elementary learners can pick up and use. (Natural English, 2012)

Grammar constitutes one of the basic elements of the syllabus.

A proven balance of skill work, grammar, vocabulary, and pronunciation your students need to talk. (English file, 2012)

In-depth treatment of grammar. (New Headway, 2011)

Likewise preceding decades, integration of skills is underscored in the blurbs.

Integrated skills throughout. (New Headway, 2011)

Students' and teachers' needs are regarded as a basis of curriculum development.

The headway course is renowned worldwide for its clear understanding of teacher and learner needs. (New Headway, 2011)

English file third edition continues with the concept of fun, enjoyable lessons that get students talking and blends it with the new mobile and digital solutions to respond to the changing needs of today's teachers and learners. (English file, 2012)

\section{Discussion}

This paper was to explore the schematic structure of the blurbs along with word concordances as a reflection of theories-in-use of ELT community in the back cover blurbs of ELT books across four decades. Analysis of the corpus indicated a 6-move organization of blurbs including advertising a book by selecting a slogan, establishing a niche, specification of the content, presentation of other components in the package, author endorsement, and propagating the book by means of extracts from teachers and students' praise the overall purpose of which was to introduce the book and persuade the readers. Comparisons of the generic make-up amongst the decades indicated no significant changes in the obligatory moves of the genre (Move 2, 3, and 4) except for the addition of new items of digital resources and technological advancements and shorter length of Moves 2 and 3 for better usage of back cover space. Additionally, two optional moves (slogan presentation and extracts from teachers and students' compliments) have been added to the newly published text books to further advertise the book and make it more influential.

The schematic structure derived from this study is much similar to the one presented by Basturkman (1999) in that, she identified our second move (establishing a niche) as "situating the book as a product", a construct which determines "the conceptualizations of what constitutes valid or proper aims and units of delivery in language education." (p. 24). The next move which she defined as "situating the text as a process" serves to underscore the language and learning theories presupposed in the construction of the material which constitute our content specification move. Akin to our author endorsement move, her third move validates the textbook by associating it to the expertise and knowledge of the authors and similar to our study, the next move notifies the readership of the other items in the course. Delineating methodological foundations of the course and the 
A generic and corpus analysis of ELT blurbs across four decades

approach to accomplish language learning in our data was considered as a step fluctuating between the second and the third move while in Basturkman's, it was considered as a step included in the second move.

Examination of the contextual settings in which key words of language elements occurred also uncovered several important facts about the ELT community's praxis. First, unlike Basturkman who argued for an a-theoretical tendency in the ELT community, the results of our analysis indicated that the theories are well-reflected and well-documented in the back cover blurbs. Her claim was based on the observation that only one move in the generic construction tackled the theories of language learning and that less than half of the blurbs explicitly referred to the theoretical aspects of their endeavor. However, it was illustrated in our results that the ELT community adjusts itself to some shifting swings of the theory pendulum as they appeared and vanished. During 1980s, for example, comprehensive and detailed explanation of grammar was a primary objective but more inductive teaching strategies were welcomed in the later decades. Functions, once considered a key element of the syllabus in 1980s, were coordinated with more task-oriented moves in more recent years. Vocabulary having been considered as an important dimension of syllabus has been extended from distinct words to greater lexical chains and pre-fabricated phrases (Lewis, 1993).

In addition, the scope of syllabus has been widened from incorporating the only constructs of structure, lexis, and function to more aspects of topic, tasks, functions, and other features of language system. More recent trends of corpus linguistics have also affected the content specification of the syllabus and this fact is explicitly demonstrated in the blurbs. Furthermore, the concept of authenticity has been revisited from authenticity of texts- those written not for the purpose of language teaching but for real-life communicative purposes- to learner authenticity and authenticity of tasks. Authentic tasks involve learners in interaction with materials which is achieved through appropriate response and positive psychological reaction (Widdowson, 1980; Lee, 1995).

The orientation towards skills was also altered from provision and systematic development of distinct skills in isolation to the integrated presentation of all four skills and sub-skills which was regarded as a pre-requisite for purposeful communication and developing learners' proficiency. Additionally, high collocation of the entry "balance" with skills in 1990s and afterwards implies that listening and reading were no longer considered as secondary Cinderella skills (Nunan, 2002) to be given less priority in a language course. Furthermore, in the earlier decades (1980s), culture was considered as mainstream native-like norms of social life and behavior with the resultant peripheralizing learners' own cultural values. In this perspective, learning a foreign language equals "a kind of enculturation, where one acquires new cultural frames of reference and a new worldview, reflecting those of the target language culture and its speakers" (Alptekin, 2002, p. 58). However, greater recognition of the status of English as a lingual franca changed the purpose of cultural instruction to empowering the learners to cope with socio-pragmatic failure and breakdowns in communication by inclusion of more elements of global culture.

The other change in the blurbs reflecting the underlying theoretical adjustment is the great emphasis on the meaningfulness of tasks and activities. This suggests the fact that mechanical drills and exercises were no longer conceived of as valuable by the ELT community but instead attention was paid to the extralinguistic contexts in which language occurred with the aim of presenting learners with comprehensible input and providing conditions for acquisition to take place (krashen \& Terrell, 1983). All these implicit and explicit citations of theories point to the fact that the ELT community has not been unaffected by the trendy transitions in theories and contending that "the ELT community does not universally need or want to directly align itself with particular theoretical stance" (Basturkman, 1999, p. 33) cannot be a tenable premise.

However, claiming that the ELT community has embraced blind acceptance of all theories is also going too far. Some other pieces of evidence in our data further suggest that the ELT community has adopted a selective approach towards theoretical paradigms. In fact, those theories which have been proven practical and sensible in the classroom level have been selected and employed while others have been discarded. For instance, the idea put forward by proponents of communicative approach that linguistic forms were acquired by "seeking 
situational meaning, that is [...] incidentally rather than as a result of focusing directly on linguistic form" (Schmidt, 1991, p. 1.2.2) was not received favorably by the ELT community. Instead, as our analysis demonstrated, no era was completely devoid of structural presentation and that language was viewed to consist primarily of grammatical structures and to a lesser degree, vocabulary (Basturkmen, 1999). Even for those courses claimed to be solely based on communicative approach, grammar functioned as a foundation on which communicative syllabus was based.

Likewise, whilst the state-of-the-art of teaching phonological aspects gives prominence to overall intelligibility rather than native-like accent modification (McKay, 2002; Tarone, 2005) thorough pronunciation practice is still one of the fundamental goals of language pedagogy even during the last years. The reason for such an extensive focus may be that L2 pronunciation is deemed to be intimately linked with the listening process (Gilbert, 1984, 1987) and with communicative speaking activities (Acton, 1984; Celce-Murcia, 1987; Pica, 1984). It is also believed to contribute to students' attaining better affective states (Stevick, 1978) and higher self-esteem. Taking these arguments into account, it can be concluded that the ELT community selects what represents appropriate, relevant, and effective instruction. That is to say, it exercises "principled eclecticism" (Larsen-Freeman, 2000) by blending the most feasible aspects of theories and methods in a principled manner. Therefore, the ELT community values practical solutions (Basturkmen 1999) not by turning a blind eye towards the existing trends or by disassociation of theory from practice but by a careful selection of realistic aspects of theories. Its appeal seems to be for materials that are practical at classroom level and establish in students a repertoire of communicative skills.

\section{Conclusions}

This study sought to shed light on the theories-in-use of the ELT community by analyzing the back cover blurbs of ELT books from the last four decades in terms of their generic construction and word concordance. Whereas the results pointed the selective application of some theories in organizing back covers, it did not explore why some other useful theories were not embraced fully throughout the blurbs. Further lines of research are required to identify the issue more clearly. Additionally, our corpus covered only course books published in1980s and onwards and while the preceding decades have witnessed more paradigm shifts, most theoretical considerations proposed in this time overlap considerably. Consequently, we normally missed a very large part of the picture of the congruence between theories and practice from the past years. Further inquiries can compensate for the loss by inclusion of the corpus and publications from more previous decades. Nevertheless, the results presented here can provide significant understandings to the theorists of what constitutes rational and practical premises and what is not of value to the ELT community. Furthermore, it raises teachers' and students' awareness of reasonable components of language pedagogy. In addition, it assists textbook publishers in how to organize an effective and space-saving blurb which exerts the greatest influence on readership and opens its market niche.

\section{References}

Acton, W. (1984). Changing fossilized pronunciation. TESOL Quarterly, 18(1), 71-86. http://dx.doi.org/10.2307/3586336

Alptekin, C. (2002). Towards intercultural communicative competence in ELT. ELT Journal, 56(1), 57-64. http://dx.doi.org/10.1093/elt/56.1.57

Basturkmen, H. (1999). A content analysis of ELT textbook blurbs: Reflection of theory-in-use. RELC journal, 30(1), 18-38. http://dx.doi.org/10.1177/003368829903000102

Bhatia, V., K. (1993). Analyzing genre: Language use in professional settings. London and New York: Longman.

Celce-Murcia, M. (1987). Teaching pronunciation as communication. In J. Morley (Ed.), Current perspectives on pronunciation (pp. 1-12). Washington, DC: TESOL.

Dudley-Evans, A. (1994). Genre analysis: an approach to analysis for ESP. Advances in Written Text Analysis. Edited by M. Coulthard. London: Routledge. 
A generic and corpus analysis of ELT blurbs across four decades

Kathpalia, S., S. (1997). Cross-cultural variation in professional genres: A comparative study of book blurbs. World Englishes, 16, 417-26. http://dx.doi.org/10.1111/1467-971X.00075

Krashen, S., D., \& Terrell, T. D. (1983). The Natural Approach: Language acquisition in the classroom. New York: Alemany Press.

Larsen-Freeman, D. (2000). Techniques and principles in language teaching (2nd ed.). Oxford: Oxford University Press.

Lee, W. Y. (1995). Authenticity revisited: text authenticity and learner authenticity. ELT Journal, 49(4), 323-328. http://dx.doi.org/10.1093/elt/49.4.323

Lewis, M. (1993). The lexical approach: The state of ELT and a way forward. Hove, England: Language Teaching Publications.

Gea-Valor, M., L. (2005). “Advertising books: A linguistic analysis of blurbs”. Ibérica 10, 41-62.

Gilbert, J., B. (1984). Clear speech: Pronunciation and listening comprehension in American English. New York: Cambridge University Press.

Gilbert, J. B. (1987). Pronunciation and listening comprehension. In J. Morley (Ed.), Current perspectives on pronunciation (pp. 29-40). Washington, DC: TESOL.

Marckwardt, A. (1972). Changing winds and shifting sands. MST English Quarterly, 211, 3-11.

McKay, S. (2002). Teaching English as an international language. Oxford: Oxford University Press.

Nunan, D. (2002). Listening in language learning. In J. Richards \& W. Renandya (Eds.), Methodology in language teaching: An anthology of current practice (pp. 238-241). NY: Cambridge University Press. http://dx.doi.org/10.1017/CBO9780511667190.032

Pica, T. (1984). Pronunciation activities with an accent on communication. English Teaching Forum, 22(3), 2-6.

Önder, N. (2013). Generic structure and promotional elements in best-selling online book blurbs: a cross-cultural study. Ibérica, 25, 171-194.

Robinson, V. (1993). Problem based methodology. Oxford: Pergamon Press.

Santos, M. (1996). The textual organization of research paper abstracts in applied linguistics. Text, 16(4), 81-499. http://dx.doi.org/10.1515/text.1.1996.16.4.481

Schmidt, R. (1991). Input, interaction, attention and awareness: The case for consciousness raising in second language teaching (Anais do X Encontro Nacional de Professores Universitáros de Língua Inglesa 1). Rio de Janeiro, Brazil: Pontifícia Universidade Católica.

Stern, H. (1985). Review of Methods that work: A smorgasbord of ideas for language teachers. Studies in Second Language Acquisition, 7(2), 249-251.

Stevick, E., W. (1978). Toward a practical philosophy of pronunciation: Another view. TESOL Quarterly, 12(2), 145-150. http://dx.doi.org/10.2307/3585605

Swales, J., M. (1990). Genre analysis: English in academic and research settings. Cambridge: Cambridge University Press.

Tarone, E. (2005). Speaking in a second language. In E. Hinkel (Ed.), Handbook of research in second language teaching and learning (pp. 485-502). Mahwah, NJ: Lawrence Erlbaum.

Todova, E. (1997). Capulet and Montague - reconciled and ennobled: recognizing the existence of a balanced approach with CLT. Journal of Communication and International Studies, 127-134.

Widdowson, H., G. (1980). The authenticity of language data. In H. G. Widdowson. Explorations in Applied Linguistics. Oxford: Oxford University Press.

Yunxia, Z. (1997). An analysis of structural moves in Chinese sales letters. Text 17(4), 543-566. http://dx.doi.org/10.1515/text.1.1997.17.4.543 
Chahkandi, F., \& Zeinali, M. 